\title{
ESTUDO INTRODUTÓRIO DA SOLDABILIDADE DO AÇO 22MnB5 PELO PROCESSO DE SOLDAGEM A PONTO POR RESISTÊNCIA
}

Advan Coelho Nascimento1; Francisco Magalhães dos Santos Junior²; Leonardo Oliveira Passos da Silva²; Rodrigo Santiago Coelho²

${ }^{1}$ SENAI CIMATEC, Av. Orlando Gomes, 1845 - Piatã, 41650-010; Salvador/Bahia; advankoelho@gmail.com

2 SENAI CIMATEC, Av. Orlando Gomes, 1845 - Piatã, 41650-010; Salvador/Bahia;

Resumo: A soldabilidade é um fator importante na união de chapas de materiais metálicos na indústria automotiva, sobretudo quando se trata de aços avançados de alta resistência. Desta forma, este trabalho busca estudar os resultados do processo de soldagem a ponto por resistência (RSW), em aço 22MnB5 galvanizado. Foi verificado o comportamento das juntas soldadas, para diferentes correntes de soldagem, utilizando-se ensaios visuais, metalográficos e de microdureza. Os resultados mostraram que a elevação da corrente de soldagem, associada à presença do zinco no revestimento do aço, levou a uma série de defeitos e descontinuidades e, ainda, variações significativas no tamanho da zona fundida e da zona termicamente afetada.

Palavras-Chave: Soldagem a ponto por resistência; Corrente de soldagem; Lentilha; Soldabilidade; 22MnB5.

\section{INTRODUCTORY STUDY OF 22MnB5 STEEL WELDABILITY BY RESISTANCE SPOT WELDING PROCESS}

\begin{abstract}
Weldability is an important factor in the joining of sheet metal in the automotive industry, especially when it comes to advanced high strength steels. Thus, this work aims to study the results of the resistance spot welding (RSW) process in $22 \mathrm{MnB5}$ galvanized steel. The behavior of the welded joints for different welding currents was verified using visual, metallographic and microhardness tests. The results showed that the increase of the welding current, associated with the presence of zinc in the steel coating, led to a series of defects and discontinuities, as well as significant variations in the size of the fused zone and the thermally affected zone.
\end{abstract}

Keywords: Resistance spot welding; Welding current; Lentil; Weldability; 22MnB5. 


\section{INTRODUÇÃO}

A indústria automotiva, com o passar dos anos, precisou buscar por melhorias tecnológicas na utilização de novos materiais, a fim de reduzir o peso e custos dos veículos e aumentar os níveis de segurança dos passageiros. Com isso, novas soluções, como os aços avançados de alta resistência (AHSS), passaram a ser objetos de estudo na construção de componentes estruturais e de reforço dos automóveis [1].

Entretanto, o aço 22MnB5 é uma opção importante para essa indústria, já que possui uma resistência mecânica que pode ultrapassar $1.500 \mathrm{Mpa}$, e, assim, atender à demanda automotiva. Este aço é definido como aço ao boro, caracterizado por boa formabilidade no estado laminado a quente. Esta característica está relacionada à microestrutura ferrítica-perlítica e à elevada resistência pós têmpera, o que reduz o retorno elástico [2].

Diante da necessidade de unir as peças compostas por esses materiais na indústria automotiva, a soldagem a ponto por resistência (RSW) é o processo mais utilizado para este fim. Quando comparado aos processos de soldagem a arco elétrico, RSW é um processo mais barato, robusto e de fácil automatização [3]. Esta técnica depende da combinação de diversos fatores e parâmetros de soldagem, como corrente elétrica, propriedades elétricas e térmicas do aço, dentre outros. Essas variáveis, quando bem definidas, darão origem à lentilha, que deverá ter a geometria e as propriedades adequadas à sua aplicação [4].

A soldabilidade dos aços $22 \mathrm{MnB} 5$ pode ser prejudicada quando se encontra em estado temperado. Os efeitos do revenimento não-isotérmico podem ocorrer na zona termicamente afetada (ZTA), devido a temperaturas menores que a temperatura final de transformação austenítica (Ac1) durante a soldagem. Com isso, a resistência mecânica dessa região pode ser reduzida, em relação ao metal de base, que foi fortemente endurecido pela estampagem a quente [5]. O estudo de caso, o qual o aço AHSS TRIP 800 não passou pelo processo de estampagem, teve, como resultado da soldagem por RSW, a formação da martensita na zona fundida (ZF) e na zona termicamente afetada (ZTA), tendo como consequência a elevação da microdureza nessas regiões [6].

Considera-se que, atualmente, o uso da galvanização tem se tornado comum nesses aços, por promover uma boa resistência à corrosão, aliada a um custo relativamente baixo. Mas a utilização desse revestimento, geralmente com zinco $(\mathrm{Zn})$, pode levar a inconvenientes durante a soldagem [7]. A presença de revestimentos galvanizados com zinco torna a soldagem mais difícil, pois exige maior controle dos parâmetros de processo e estreitamento da faixa de soldabilidade, além de ser prejudicada à medida que a espessura do revestimento aumenta [6]. Isto ocorre devido a formação do anel de zinco na periferia da lentilha durante o aquecimento e aplicação da força pelo eletrodo. Essa região, composta por zinco, que circunda a lentilha, contribui para desviar a corrente de soldagem do ponto de solda, o que exige um incremento deste parâmetro [8]. As condições de soldagem para o aço com revestimento diferem para os aços não revestidos por causa das diferenças entre as 
condutividades elétricas e dos pontos de fusão da camada revestida e do substrato [9].

Diante do exposto, o presente artigo consiste em estudar os resultados do processo RSW para os aços 22MnB5 revestidos em Zn-Fe e a influência da variação da corrente elétrica nas propriedades deste aço.

\section{MATERIAIS E MÉTODOS}

Para este estudo, foram utilizadas quatro chapas de aço 22MnB5 de 1,8 mm de espessura, revestidas com Zn-Fe, com dimensões de $300 \mathrm{~mm} \times 100 \mathrm{~mm}$, sendo duas chapas com revestimento de $45 \mathrm{~g} / \mathrm{m}^{2}$ e as outras duas com revestimento $80 \mathrm{~g} / \mathrm{m}^{2}$.

As chapas de $45 \mathrm{~g} / \mathrm{m}^{2}$ foram sobrepostas e soldadas e, assim, três lentilhas foram formadas, dando origem aos corpos de prova C45-1, C45-2 e C45-3. O mesmo foi feito com as chapas de $80 \mathrm{~g} / \mathrm{m}^{2}$, só que desta vez deram origem a C80-1, C80-2 e C80-3.

Os corpos de prova foram produzidos variando-se a corrente elétrica, conforme a Tabela 1, e mantendo-se constante os outros parâmetros de soldagem. O modelo da máquina utilizada foi Marimax MPR 150 kVA, potência utilizada de 60\%.

Tabela 1. Correntes de soldagem utilizadas para a produção dos corpos de prova

\begin{tabular}{|c|c|}
\hline Corpo de Prova & Corrente (kA) \\
\hline C45-1 & \multirow{2}{*}{30} \\
\hline C80-1 & \\
\hline C45-2 & \multirow{2}{*}{32,5} \\
\hline C80-2 & \\
\hline C45-3 & \multirow{2}{*}{35} \\
\hline C80-3 & \\
\hline
\end{tabular}

Após as soldagens, foi realizada inspeção visual dos pontos de solda para verificar o aspecto da lentilha e possíveis defeitos e descontinuidades, como, por exemplo, presença de expulsão de material, de vazios na ZF e presença de zinco na região adjacente da solda.

Os pontos de solda foram cortados e embutidas em baquelite e, em seguida, as amostras foram lixadas e polidas para possibilitar realização dos ensaios metalográficos e de microdureza, procedida de ataque em reagente Nital $2 \%$, por 5 segundos.

No ensaio macrográfico foram medidos o comprimento da ZF e o tamanho da ZTA, utilizando-se estereoscópio óptico ECAFIX Leica M3C. Além disso, a presença de descontinuidades e defeitos de soldagem também foram alvos desse ensaio. 


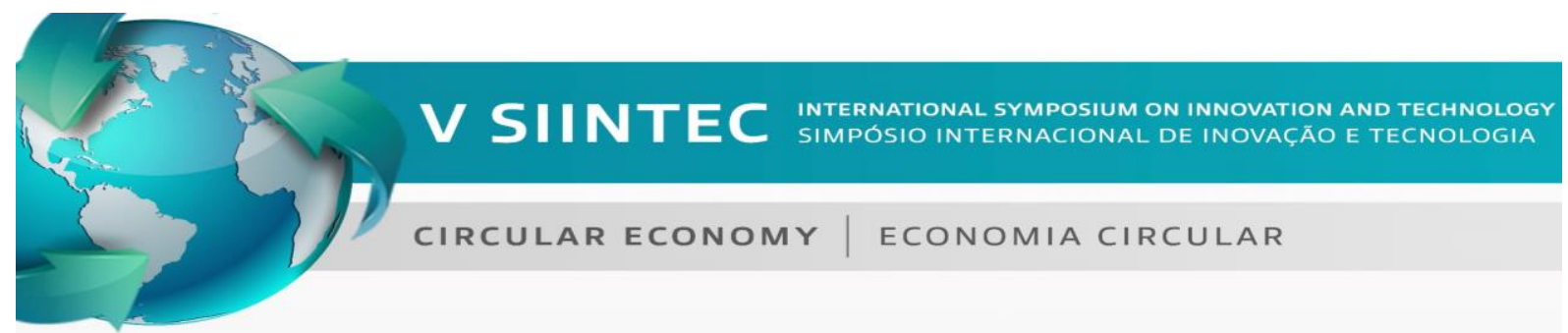

Posteriormente, a amostra foi levada ao microscópio óptico Zeiss Axio Scope. A1. Com o auxílio desse equipamento, foi possível fazer um estudo dos produtos metalúrgicos, permitindo que fossem observados a granulação do material, a natureza, forma e distribuição de diversos constituintes, defeitos e descontinuidades.

O ensaio de microdureza Vickers foi realizado com as mesmas amostras utilizadas nos ensaios metalográficos, aproveitando, dessa forma, a preparação da superfície. Usado durômetro HMV Shimadzu, com resolução de 0,09 $\mu \mathrm{m}$.

\section{RESULTADOS E DISCUSSÃO}

\subsection{Inspeção Visual}

Foi verificado o aspecto das lentilhas e identificada coloração amarelada em todos os pontos de solda e regiões adjacentes (Figura 1), o que pode indicar a presença de zinco na zona fundida e na região periférica da lentilha. Essa área, formada pelo zinco, que circunda a solda, é chamada de anel de zinco e é resultante da fusão do revestimento seguido do deslocamento para as bordas da lentilha, através da força exercida pelos eletrodos [8].

Figura 1. Lentilhas dos corpos de prova
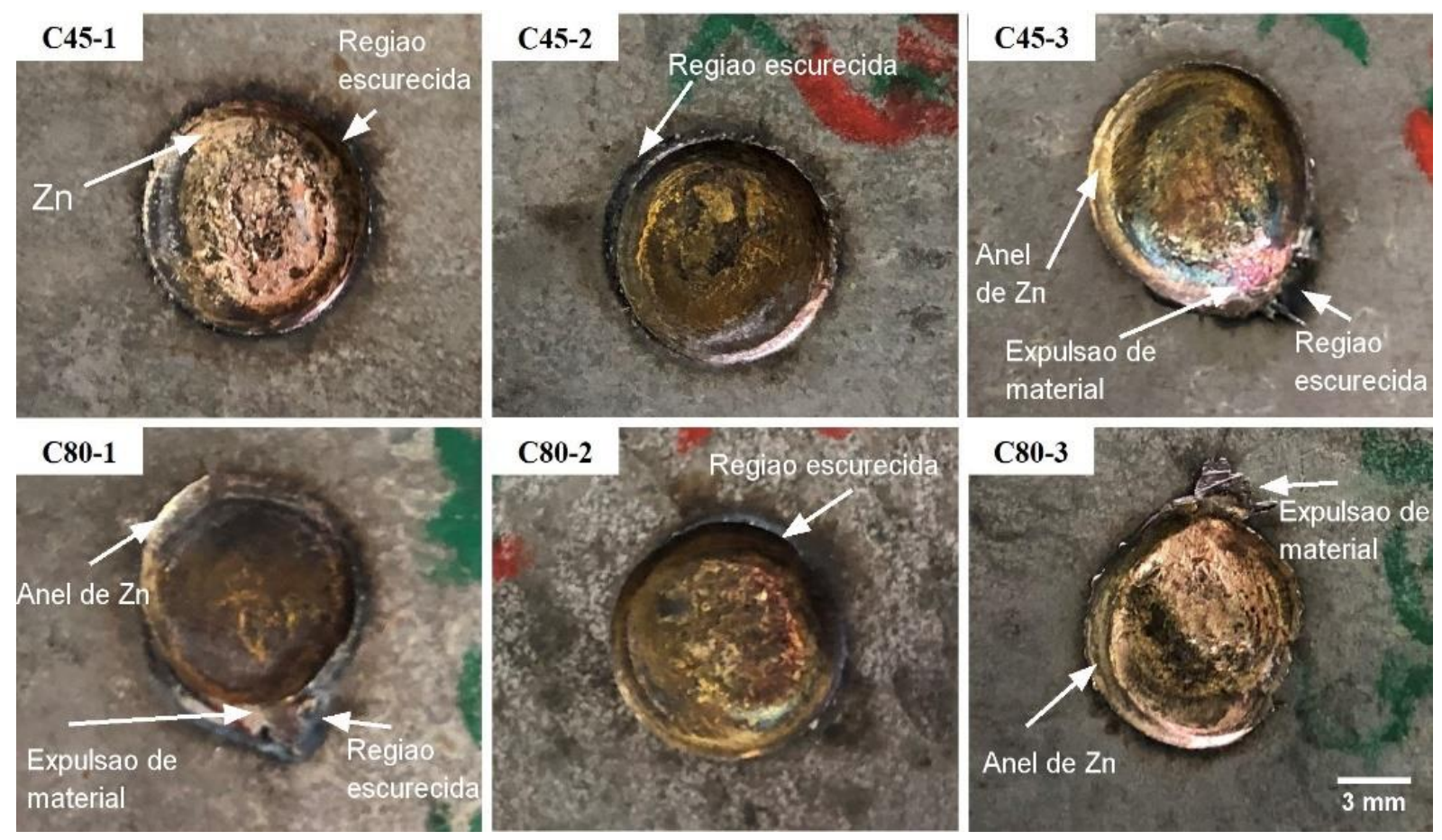

Observado, também, nas imagens da Figura 1, manchas com aspecto escurecido nas bordas das soldas, justamente, nas proximidades do anel de zinco. 
Pode-se relacionar essa ocorrência ao desvio de corrente elétrica da zona fundida para esta região adjacente, favorecido pela maior condutividade elétrica do zinco.

Visualizada, ainda, na Figura 1, expulsão de material nas amostras C45-3, C801 e C80-3, possivelmente, devido a correntes elétricas elevadas durante o processo de soldagem.

\subsection{Estudo da Macroestrutura}

Visto, durante a análise macroestrutural, que houve redução no comprimento da ZF (Figura 2a) à medida que a corrente de soldagem foi elevada. Isso pode ter ocorrido devido a expulsão de material, já evidenciada durante a inspeção visual, que causou a perda de massa do interior da lentilha para regiões adjacentes dela. $\mathrm{O}$ esperado seria um aumento no comprimento da zona fundida, pois incrementos na corrente acarretaria em maior densidade de corrente para formação da lentilha, elevando a sua dimensão.

Figura 2. Efeito da corrente de soldagem na extensão das regiões: (a) comprimento da ZF,

(b) tamanho da ZTA

(a)

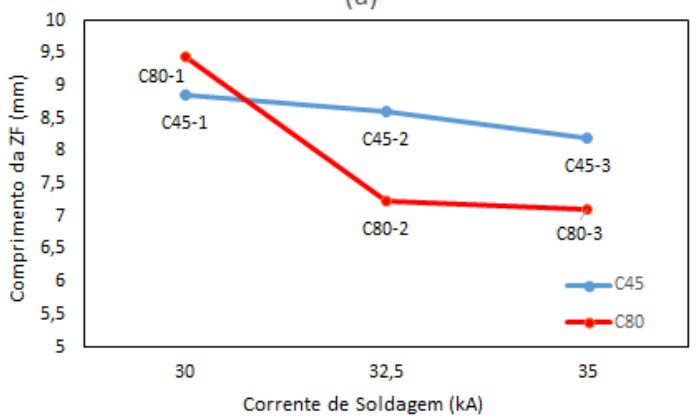

(b)

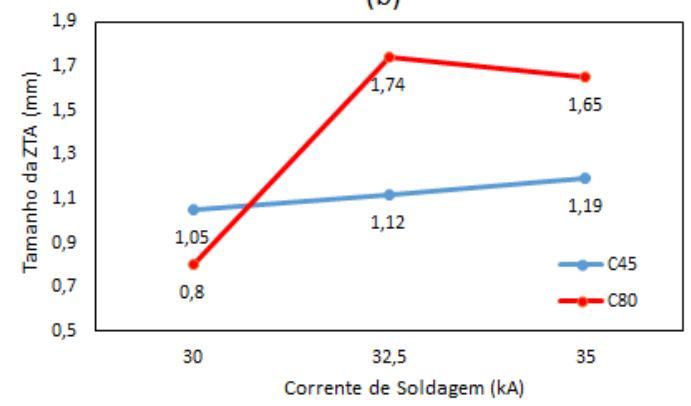

Analisando o tamanho da ZTA (Figura 2b), pode ser notado que houve um aumento dessa região cada vez que a corrente de soldagem foi elevada. Apesar dessa relação ser esperada, ainda assim, incrementos de calor, devido ao anel de zinco, pode ter contribuído ainda mais para o aumento na geometria desta zona.

As amostras com revestimento de $45 \mathrm{~g} / \mathrm{m}^{2}$ apresentaram, no geral, valores maiores de comprimento da ZF e menores de tamanho de ZTA, quando comparadas com as amostras de $80 \mathrm{~g} / \mathrm{m}^{2}$. Isso se deve, possivelmente, à quantidade de $\mathrm{Zn}$ presente no revestimento e que, em certa proporção, nas amostras de $80 \mathrm{~g} / \mathrm{m}^{2}$, a sua presença foi maior na formação de anel de zinco. Portanto, um maior desvio de corrente pode ser responsável por uma menor ZF e, consequentemente, uma maior ZTA nas amostras de $80 \mathrm{~g} / \mathrm{m}$.

A Figura 3 ilustra a seção transversal das amostras C45-1, C45-3 e C80-3, as quais apresentaram vazios na lentilha, caracterizados, provavelmente, pela expulsão do material. Além de vazios, várias trincas puderam ser vistas na ZF das amostras. 


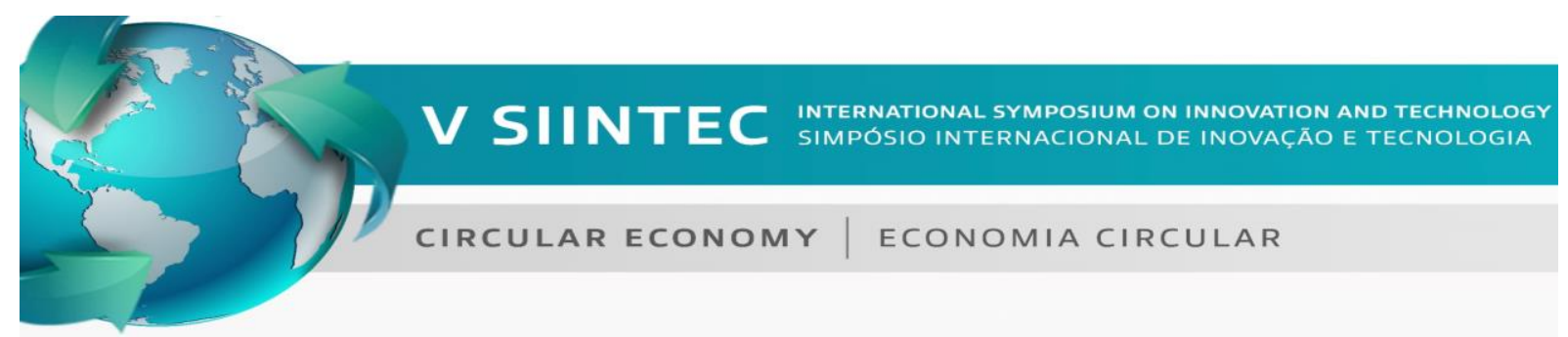

Figura 3. Macrografias da seção transversal: (a) C45-1, (b) C45-3 e (c) C80-3.
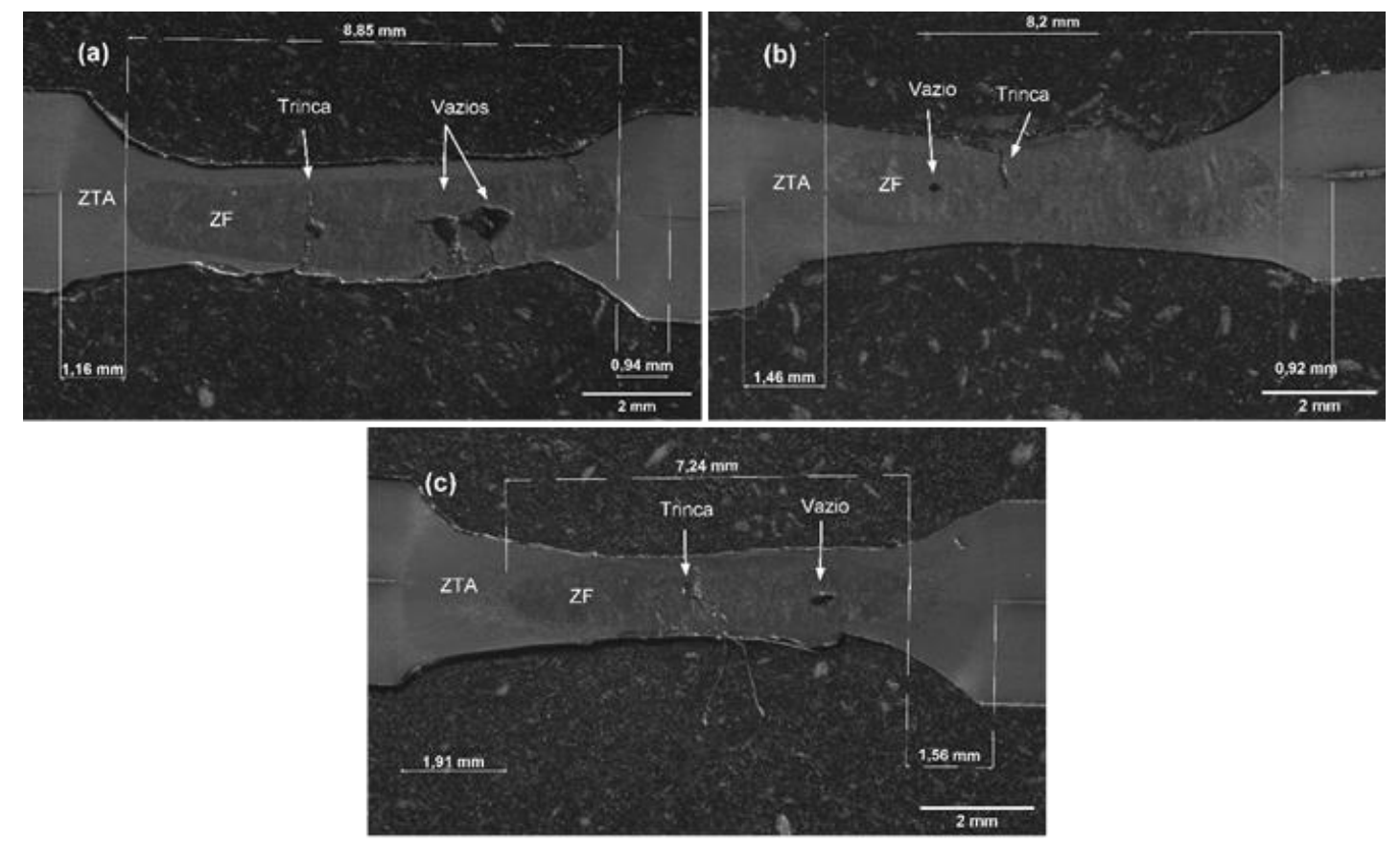

\subsection{Estudo da Microestrutura}

Durante o estudo micrográfico, foi investigado o revestimento de zinco na periferia da lentilha. Observou-se que à medida que a corrente de soldagem foi elevada, a quantidade de zinco tornou-se menor nas regiões adjacentes da lentilha. Isso ocorreu, possivelmente, devido a queima do zinco e, conseguinte, evaporação deste componente. A presença de camadas de $\mathrm{Zn}$ pode ser confirmada nas micrografias da Figura 4.

Figura 4. Micrografias da região de interface da ZF com a superfície revestida
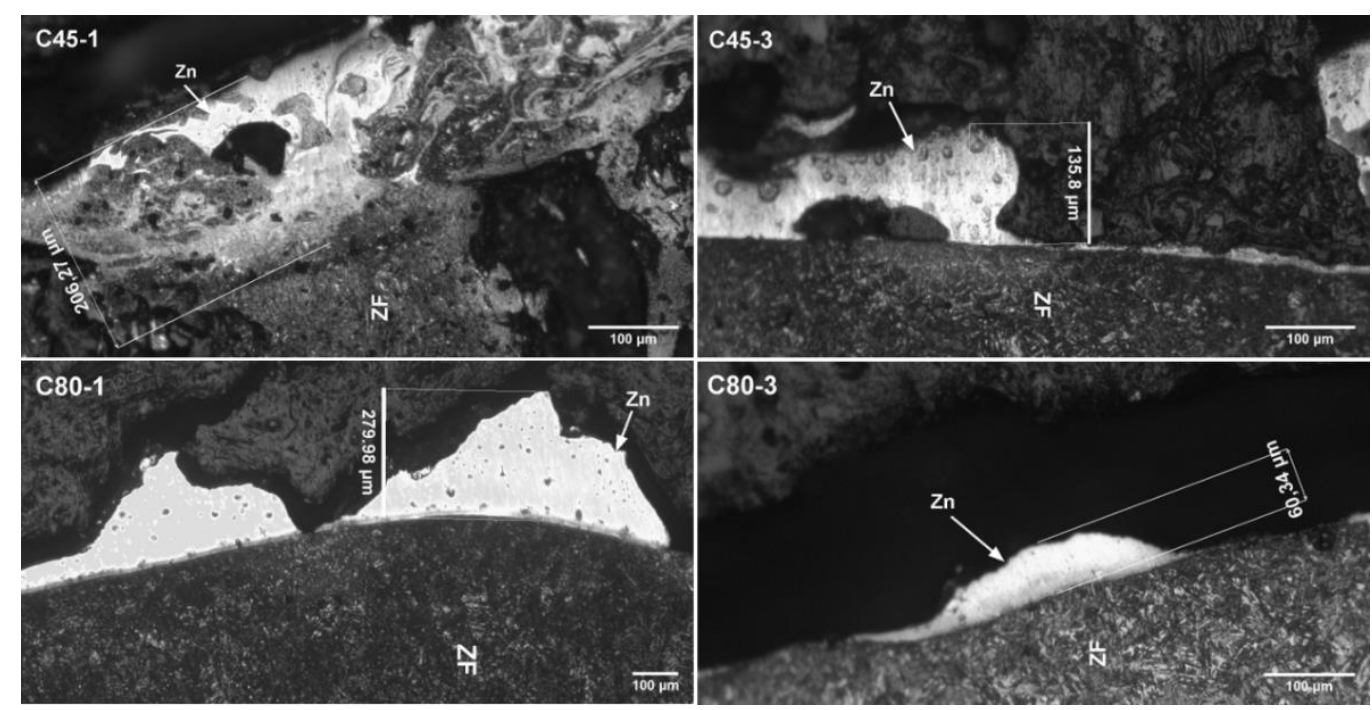


\subsection{Ensaio de Microdureza Vickers}

O perfil de microdureza Vickers apresentou semelhança em todas as amostras, com elevação significativa na ZTA e ZF, em relação ao material de base. Isso evidencia uma mudança de fase com a formação de martensita na zona fundida e na zona termicamente afetada, conforme pode ser visto na Figura 5.

Figura 5. Microdureza Vickers em relação à distância ao centro da solda: (a) C45 e (b) C80
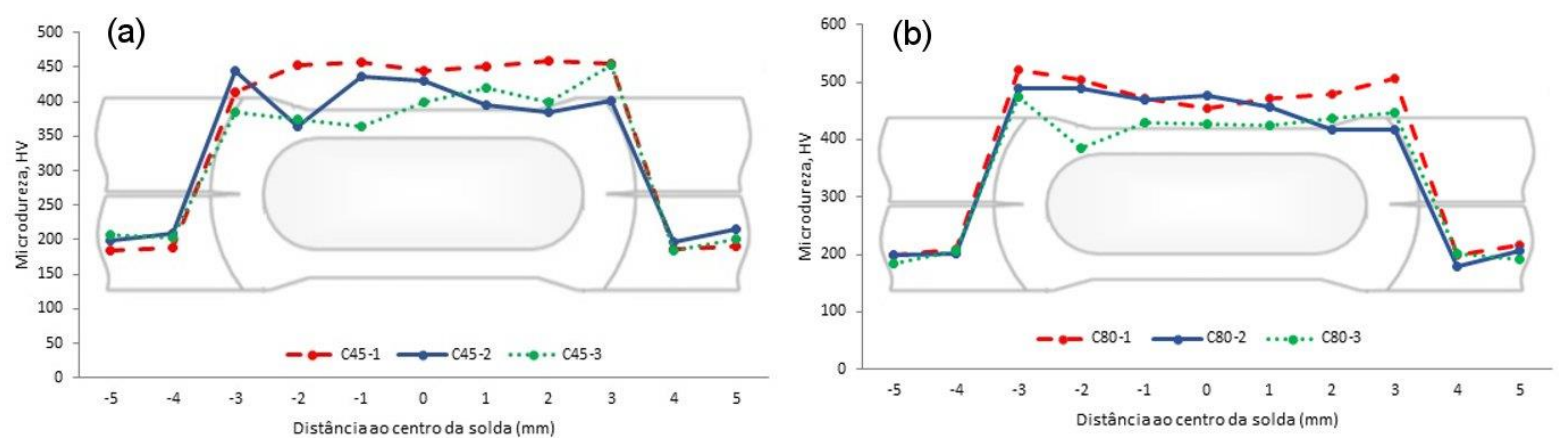

\section{CONCLUSÃO}

As dificuldades na soldabilidade do aço 22MnB5 ocorreram, em grande parte, devido a presença do zinco do revestimento. Sugere-se que esse elemento impactou na distribuição da corrente ao desviá-la do centro da lentilha para as regiões periféricas. Isso foi possível graças a maior condutividade elétrica do zinco em relação ao substrato. Essa preferência da corrente em passar por essa região foi evidenciada na inspeção visual, através da presença de manchas com aspecto escurecido ao redor da solda.

Expulsão de material, com a perda de massa do interior da lentilha, foi recorrente em algumas amostras. Elevadas correntes de soldagem foram, possivelmente, as principais responsáveis por essa descontinuidade da solda e, consequentemente, por gerar ZF menores.

No entanto, enquanto a ZF foi menor com a elevação de corrente, a ZTA se tornou maior. Esse efeito, provavelmente, teve a contribuição do anel de zinco em atrair a corrente para regiões adjacentes da lentilha, justamente onde encontra-se a ZTA. E, para reforçar ainda mais o que foi dito, as amostras dos materiais com menores concentrações de zinco no revestimento resultaram, no geral, em maiores comprimentos de ZF e menores tamanhos de ZTA, quando comparadas as amostras revestidas com mais zinco. Ou seja, quanto maior a quantidade de $Z n$ no revestimento, maior o efeito no desvio de corrente para regiões adjacentes da solda. E ainda, quanto maior a corrente, menor a quantidade de Zn na periferia do ponto de solda, devido a evaporação deste elemento. 


\section{\begin{tabular}{l|l} 
CIRCULAR ECONOMY & ECONOMIA CIRCULAR
\end{tabular}}

Ocorreu uma elevação na dureza da ZF e ZTA, devido à formação de martensita, já o metal de base se manteve com dureza característica de ferríta-perlíta, portanto, menos duro.

\section{REFERÊNCIAS}

${ }^{1}$ DE MIRANDA, G. P.; MODENESI, P. J.; MARRA, K. M. Estudo da soldabilidade a ponto por resistência entre os aços 22MnB5 e DP800. 2015.

2 DIN, E. N. 10083-3: 2007-01. Steels for Quenching and Tempering - Part 3: Technical Delivery Conditions for Alloy Steels, German Version EN 10083-3: 2006, 2007.

${ }^{3} \mathrm{BACIC}$ JUNIOR, Mario. Análise da soldabilidade do aço 22MnB5 no processo de solda ponto por resistência. 2016.

${ }^{4}$ BRIJESH, V.; JAY, D.; JAYANT, A. Effect of Process Parameters for Resistance Spot Welding Process using Taguchi Method for 2.0mm Sheet Thickness. V. 6, n. 1.2017.

5 TAMIZI, M.; POURANVARI, M.; MOVAHEDI, M. Welding metallurgy of martensitic advanced high strength steels during resistance spot welding. Science and Technology of Welding and Joining, v. 22, n. 4, p. 327-335, 2017.

${ }^{6}$ ERTEK EMRE, Hayriye; KAÇAR, Ramazan. Resistance spot weldability of galvanize coated and uncoated TRIP steels. Metals, v. 6, n. 12, p. 299, 2016.

7 TURETTA, Ivonei. Análise do desgaste de eletrodos de solda por resistência a ponto em função do número de pontos soldados em chapas galvanizadas. 2015. Tese de Doutorado. Universidade de São Paulo.

${ }^{8}$ AMARAL, Fernando Ferraz. Monitoramento da Qualidade na Soldagem a Ponto por Resistência Elétrica de Chapas de Aço Galvanizadas Baseado em Análise de Experimentos. 2011.

${ }^{9} \mathrm{CHA}, \mathrm{J}$. H. A study on resistance spot weldability of aluminum coated sheet steels. Master's Thesis. Pukyong National University. 2002. 